\title{
Within and between-days repeatability and variability of plantar pressure measurement during walking in children, adults and older adults
}

Pedro S. Franco ${ }^{1,2}$, Cristiane F. Moro ${ }^{1}$, Mariane M. Figueiredo ${ }^{1}$, Renato R. Azevedo ${ }^{1,2}$, Fernando G. Ceccon ${ }^{1,2}$ and Felipe P. Carpes ${ }^{1,2^{*}}$ (D)

\begin{abstract}
Background: Previous studies discussed the repeatability and variability in plantar pressure measurement, but a few considered different age groups. Here we determine within and between-days repeatability and variability of plantar pressure measurement during gait in participants from different age groups.

Method: Plantar pressure was recorded in children, young adults and older adults walking at preferred speed in four non-consecutive days within one week. Data from 10 steps from each foot in each day were analyzed considering the different regions of the foot. Mean and peak plantar pressure and data variability were compared between the steps, foot regions and days.

Results: To describe mean and peak pressure during gait in children and adults a single measurement can be enough, but elderly will requires more attention especially concerning peak values. Variability in mean pressure did not differ between age groups, but peak pressure variability differed across foot regions and age groups.

Conclusion: One single observation can be used to describe plantar pressure during gait in children and adults. When the interest concerns older people, it might be pertinent to consider more than one day of assessment, especially when looking at peak pressure.
\end{abstract}

Keywords: Kinetics, Foot, Gait, Aging, Peak pressure

\section{Background}

Plantar pressure analysis concerns the quantification and interpretation of the force applied to the ground and its distribution over the foot plantar surface area. Among the different ways for its quantification is the use of pressure mat systems that allows not only quantification of the pressure distribution but also analysis of the specific foot regions [1-4]. Instrumentation, foot region, and number of steps are factors influencing repeatability and variability of plantar pressure measurement [1-4]. The number of steps required for characterization of

\footnotetext{
*Correspondence: carpes@unipampa.edu.br

${ }^{1}$ Applied Neuromechanics Research Group, Federal University of

Pampa,Uruguaiana, BR 472 km 592, Po box 118, Uruguaiana, RS ZIP 97500-970, Brazil

${ }^{2}$ Graduated Program in Physical Education, Federal University of Santa Maria, Santa Maria, Brazil
}

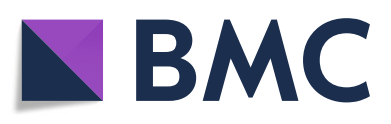

(C) The Author(s). 2018 Open Access This article is distributed under the terms of the Creative Commons Attribution 4.0 International License (http://creativecommons.org/licenses/by/4.0/), which permits unrestricted use, distribution, and reproduction in any medium, provided you give appropriate credit to the original author(s) and the source, provide a link to the Creative Commons license, and indicate if changes were made. The Creative Commons Public Domain Dedication waiver (http://creativecommons.org/publicdomain/zero/1.0/) applies to the data made available in this article, unless otherwise stated. the literature [5]. Three steps are commonly assumed in clinical analysis of gait [6], and three to five steps are assumed to be enough to record plantar pressure in adults aged 20 to 35 years old [7].

Plantar pressure variability is also a topic of interest because most of clinical decisions are based in single-day measurement. Considering data from three [4], four [4] and five [1] different days, mean pressure, peak pressure, peak force, and force-time integral showed good repeatability. However, participants of different ages were considered in each of these studies $[1,2,4]$. There is a lack of evidences concerning differences between age groups, which are especially important for studies interested in influence of age on plantar pressure. 
There are gait characteristics that influence plantar pressure in people of different ages. In children, it includes changes in body mass and contact area of the foot [8] as well the establishment of a heel-strike landing pattern $[9,10]$. Children also experience increase in peak pressure, ground reaction forces and foot length that influence center of pressure displacement [11]. Among young adults, magnitudes of pressure become stable and patterns of higher peak pressures in the rearfoot and hallux are observed [12-14]. Among older adults, a change in foot landing pattern may occur and pressure and reaction forces in the rearfoot decrease with a longer contact time [12]. These illustrate the differences between age groups that may influence plantar pressure measurements. Therefore, in this study we determine within and between-days repeatability and variability of plantar pressure measurement in people from different age groups.

\section{Methods}

\section{Participants and experimental design}

This research was conducted in agreement with the declaration of Helsinki and was approved by the local institution ethics committee. All participants and the parents (for the case of children) signed a consent term. To be included participants should be able to walk independently, be free of lower extremity injuries that limit locomotion and should be able to visit the laboratory on days previously scheduled. Those subjects that missed one evaluation session were excluded from the data analysis. Sixty participants (20 children, 20 young adults, and 20 elderly) from the local community started participation in the study. During the development of the study (see the flowchart; Fig. 1) some participants missed sessions and were excluded. In the end, 37 subjects completed all the procedures, which included 12 children, 13 adults, and 12 older adults. Participants completed four sessions of assessment in non-consecutive days within a period of 7 days for measurement of plantar pressure during walking at preferred speed.

\section{Data acquisition}

Plantar pressure was recorded during barefoot walking at preferred gait speed. Participants were requested to walk as they walk in streets. Data were acquired at $400 \mathrm{~Hz}$ using a pressure mat system (Matscan, Tekscan Inc., Boston, MA, US) placed halfway in a $9 \mathrm{~m}$ walkway. The mat had $5 \mathrm{~mm}$ thickness, detection area of $435.9 \times 368.8 \mathrm{~mm}$, comprising 2288 resistive sensors ( 1.4 sensors $/ \mathrm{cm}^{2}$ ). The system was calibrated before every evaluation for each individual using the individual body mass. Ten steps were randomly recorded for each foot, and data from right foot were considered in the analyses. Gait speed was determined using a chronometer. The evaluation session was

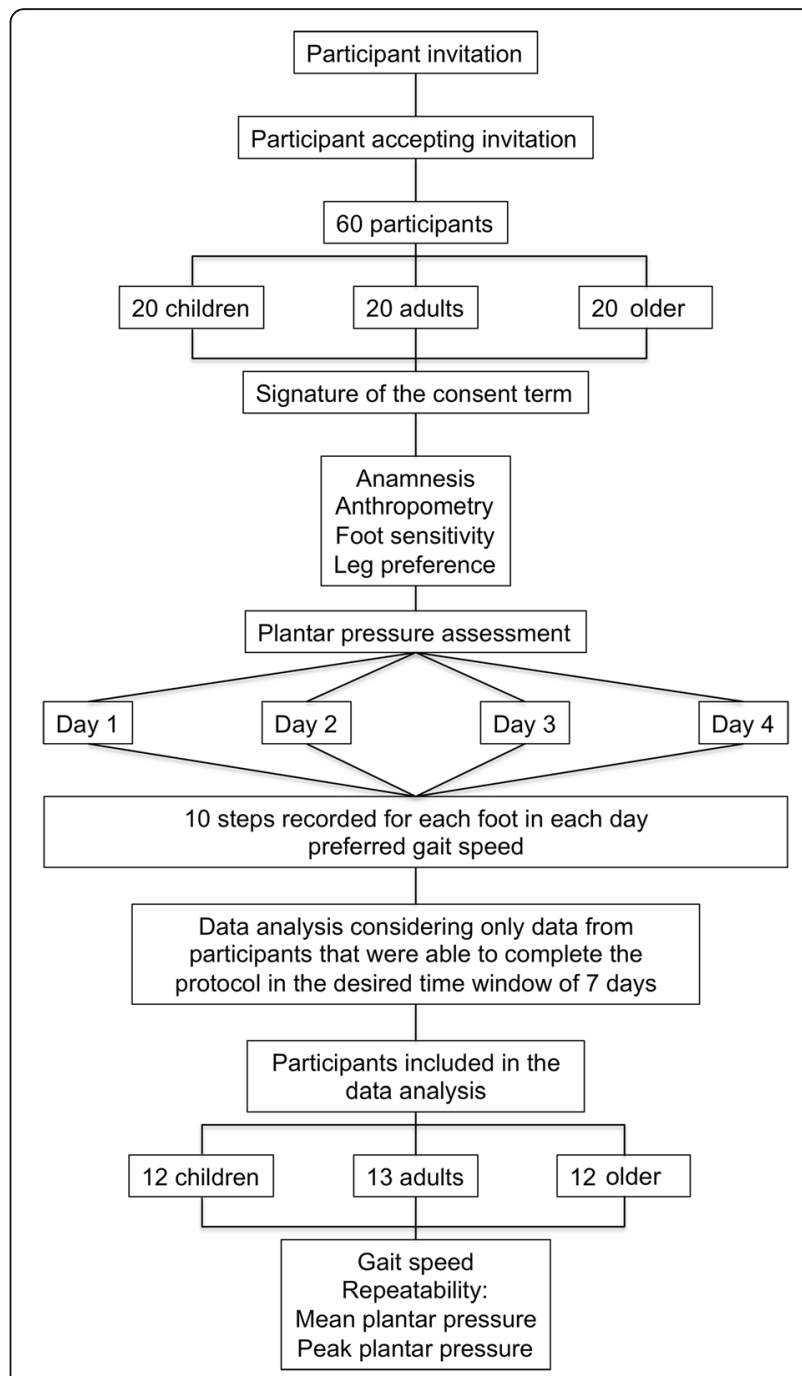

Fig. 1 The flowchart of the different phases of our study

repeated in four non-consecutives days within a period of up to 7 days.

Plantar pressure was analyzed considering the forefoot (FF), midfoot (MF) and rearfoot (RF) regions defined using a software (Research Foot 6.64, Tekscan Inc., Boston, MA, USA) and anatomical aspects determining that the rearfoot comprised $31 \%$ of the foot length, the midfoot comprised $19 \%$ of the foot length, and the forefoot comprised $50 \%$ of the foot length [15]. Data were averaged for each foot region and normalized to the total foot pressure to minimize effects body mass and foot size that differ among the participants [16]. Variables of interested in our study were mean pressure, computed by the average pressure over active sensors, and peak pressure, defined as the highest value observed among the selected active sensors [17]. Data variability was determined by the coefficient of variation that is the ratio between standard deviation and mean values. 


\section{Statistical analyses}

Data are present considering mean (standard deviation). All data were checked for normality with Shapiro-Wilk test. ANOVA one-way with Tukey post-hoc was used to compare steps and to compare foot regions within a same day of assessment. Similar approach was used to compare the different days of assessment and the different groups. All analyses considered a significance level of 0.05 using a commercial statistical package.

\section{Results}

Groups of study included 12 children [8 women; 10 (1) years old, 44 (16) kg, $1.43(0.1) \mathrm{m}$, for age, body mass and height, respectively], 13 adults [7 women; 38 (6) years old, $71(15) \mathrm{kg}, 1.65(0.1) \mathrm{m}$ ], and 12 older adults [7 women; 74 (3) years old, 70 (14) kg, $1.59(0.1) \mathrm{m}$ ]. Preferred gait speed in children was $1.21(0.1) \mathrm{m} / \mathrm{s}$, in adults was $1.56(0.2) \mathrm{m} / \mathrm{s}$, and in older adults was 0.89 $(0.10) \mathrm{m} / \mathrm{s}$. Mean pressure did not differ between the steps in both adults and older adults in within-day comparisons (Fig. 2). Among children, mean pressure differed between some of the steps only for the fourth day $\left(F_{(9)}=4.389 ; P=0.03\right.$; Fig. 2). Peak pressure did not differ between the steps in adults and older adults (Fig. 3). Peak pressure in children differed between some of the steps only in the rearfoot for the fourth day $\left(F_{(9)}=\right.$ 2.688; $P=0.04$, Fig. 3).
Regardless of the day of measurement, when comparing the foot regions, adults showed lower peak pressure in the midfoot compared to forefoot and rearfoot (Fig. 4). In children, peak pressure was smaller in the midfoot than forefoot and rearfoot, while forefoot and rearfoot showed similar values. Among older adults, peak pressures were higher in the forefoot and differed between the three regions of the foot (Fig. 4).

To compare pressure between the days we considered the average of mean and peak pressures from each day of measurement (Fig. 4). Mean and peak pressure in children did not differ between the days. Among adults, mean pressure in the midfoot was higher for the fourth day $\left[\mathrm{F}_{(3)}=5.190 ; P=0.027\right.$, while peak pressure was similar for the different days. In older adults, mean pressure did not differ between the days, but peak pressure differed between all the days $\left[\mathrm{F}_{(3)}=4.717 ; P=0.008\right]$.

Data on pressure variability were also considered in our analyses (see Table 1 for variability of mean and peak pressure). Mean pressure variability did not differ between the days of measurement in foot regions of children, adults and older adults. However, when mean pressure variability was compared between the foot regions, regardless of the day of measurement, higher variability in the midfoot, and similar variability in the rearfoot and forefoot were observed in children $\left(\mathrm{F}_{(2)}=\right.$ 36.10; $P<0.001)$, adults $\left(\mathrm{F}_{(2)}=174.1 ; \mathrm{P}<0.001\right)$, and older adults $\left(\mathrm{F}_{(2)}=125.4 ; \mathrm{P}<0.001\right)$. When groups were

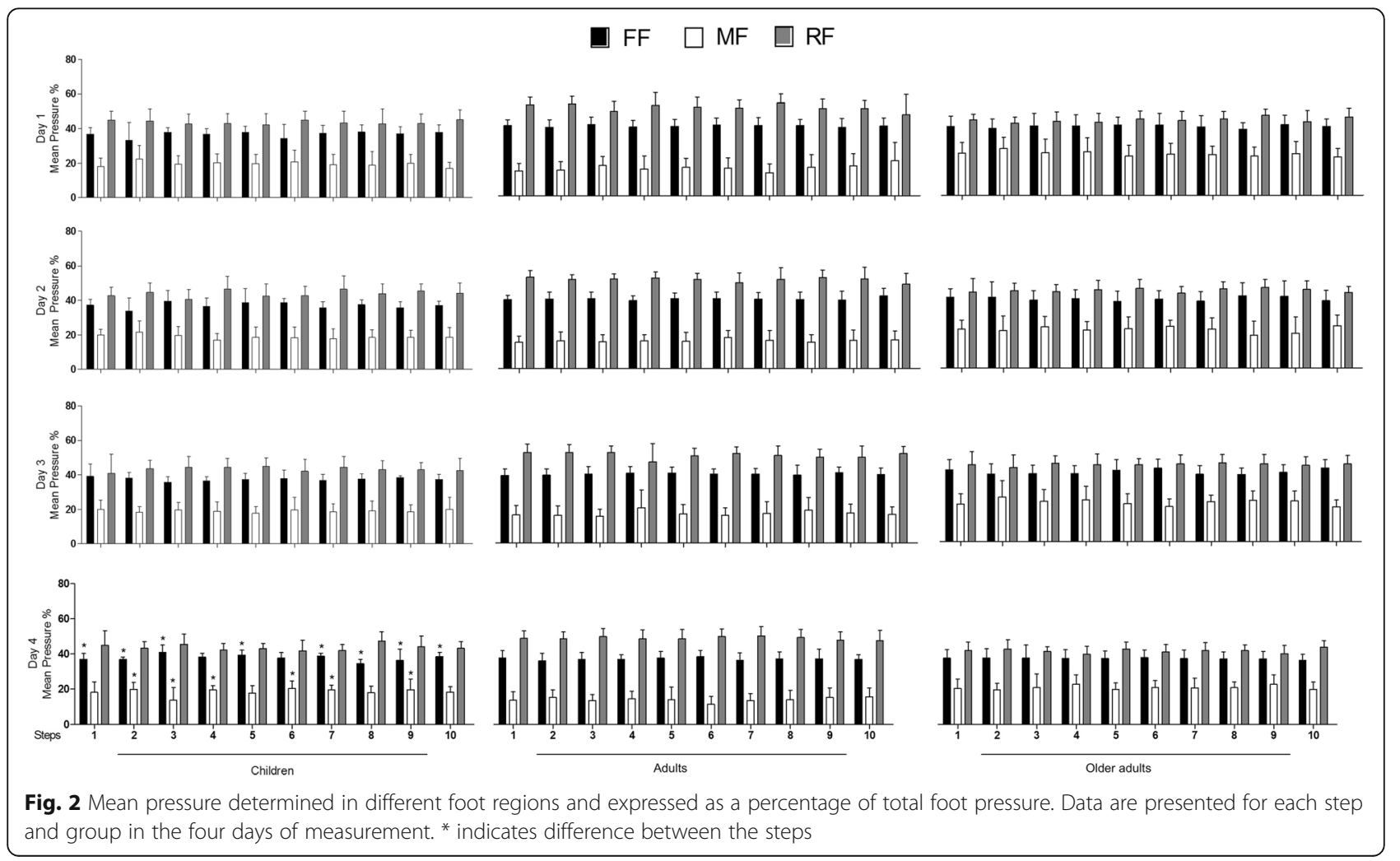



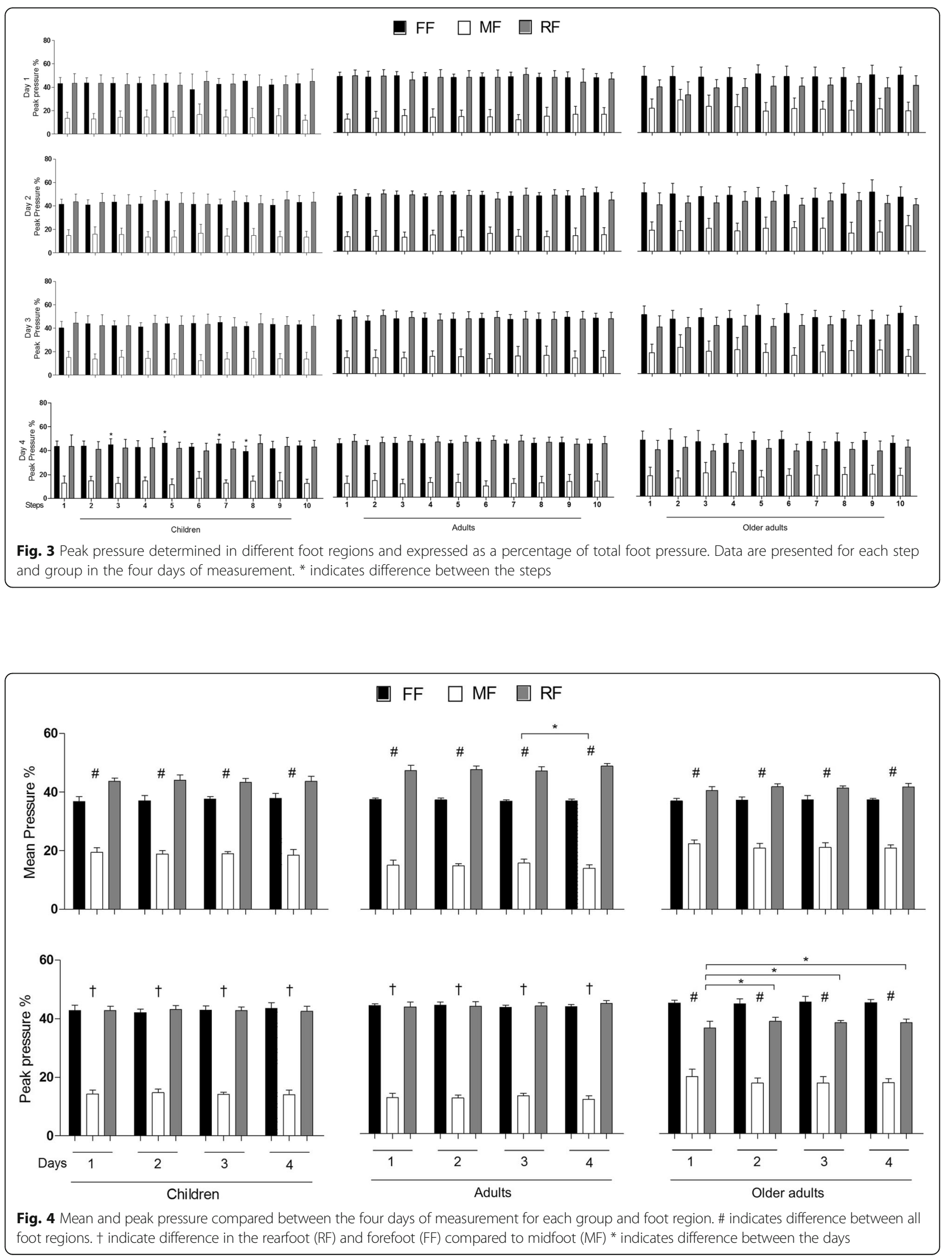
Table 1 Coefficient of variation determined for each day, foot region and group, considering data of mean and peak pressure. Data are expressed in percentage (\%) considering mean and standard deviation data from each foot region. FF: forefoot; MF: midfoot; FR: rearfoot

\begin{tabular}{|c|c|c|c|c|c|c|}
\hline Variable & Group & Foot region & Day 1 (\%) & Day 2 (\%) & Day $3(\%)$ & Day 4 (\%) \\
\hline \multirow[t]{9}{*}{ Mean pressure variability } & \multirow[t]{3}{*}{ Children } & $\mathrm{FF}$ & $13.6(7.6)$ & $12.2(5.8)$ & $9.1(3.9)$ & $7.8(4.0)$ \\
\hline & & MF & $29.5(5.9)^{*}$ & $27.0(5.7)^{*}$ & $26.6(6.1)^{*}$ & $24.6(12.3)^{*}$ \\
\hline & & RF & $14.3(2.7)$ & $13.5(2.5)$ & $14.3(5.0$ & $11.3(3.0)$ \\
\hline & \multirow[t]{3}{*}{ Adults } & FF & $10.2(1.3)$ & $9.3(1.8)$ & $9.7(2.0$ & $10.5(2.2)$ \\
\hline & & MF & $38.4(8.0)^{* \#}$ & $29.9(5.1)^{* \#}$ & $34.1(7.8)^{* \#}$ & $34.1(7.4)^{* \#}$ \\
\hline & & RF & $11.8(5.0)$ & $9.1(3.2)$ & $10.4(4.4)$ & $9.8(1.4)$ \\
\hline & \multirow[t]{3}{*}{ Older adults } & FF & $14.2(2.8)$ & $15.9(3.4)$ & $12.7(1.7)$ & $12.8(2.6)$ \\
\hline & & MF & $26.1(3.9)^{*}$ & $29.5(10.1)^{*}$ & $25.6(6.0)^{*}$ & $23.1(4.7)^{*}$ \\
\hline & & RF & $10.7(2.5)$ & $10.7(3.0)$ & $12.4(3.0)$ & $10.0(1.8)$ \\
\hline \multirow[t]{9}{*}{ Peak pressure variability } & \multirow[t]{3}{*}{ Children } & FF & $14.9(7.3)^{\$}$ & $13.5(3.7)^{\$}$ & $11.3(2.7)^{\$}$ & $10.6(2.5)^{\$}$ \\
\hline & & MF & $41.2(6.3)^{*}$ & $37.7(4.0)^{*}$ & $36.8(4.0)^{*}$ & $32.7(9.8)^{*}$ \\
\hline & & RF & $20.4(2.8)^{+}$ & $18.4(2.1)^{+}$ & $19.5(2.1)^{+}$ & $16.0(2.9)^{+}$ \\
\hline & \multirow[t]{3}{*}{ Adults } & FF & $7.9(1.4)^{\$+}$ & $6.8(1.7)^{\$+}$ & $9.9(1.8)^{\$+}$ & $8.4(1.6)^{\$+}$ \\
\hline & & MF & $43.7(6.9) *$ & $38.8(5.5) *$ & $42.6(7.7) *$ & $43.2(7.8) *$ \\
\hline & & RF & $13.4(4.5)$ & $10.2(2.8)$ & $11.9(1.7)$ & $10.4(1.4)$ \\
\hline & \multirow[t]{3}{*}{ Older adults } & FF & $17.0(1.4)^{\S+}$ & $18.0(1.8)^{\$+}$ & $15.0(1.9)^{\S+}$ & $16.0(2.3)^{\$+}$ \\
\hline & & MF & $40.8(4.8)^{*}$ & $44.2(9.7)^{*}$ & $41.5(5.1)^{*}$ & $36.3(4.8)^{*}$ \\
\hline & & RF & $19.3(5.6)$ & 16.7 (3.8) & $19.6(2.7)$ & $17.1(3.1)$ \\
\hline
\end{tabular}

* different of FF and RF $(P<0.05) ;{ }^{\$}$ different of RF and MF $(P<0.05)$; \# different of children and older adults $(P<0.05) ;+$ identify days that differed between them $(P<0.05)$

compared, the only difference relies on the mean pressure variability in the midfoot that showed an effect for age $\left(\mathrm{F}_{(2)}=8.88 ; P=0.002\right)$, being higher in adults compared to older adults. Mean pressure variability in other foot regions did not differ between groups.

Peak pressure variability differed between the days in the different groups and foot regions. In children, variability of peak pressure in the rearfoot differed between the days $\left(\mathrm{F}_{(3)}=4.84 ; P=0.015\right)$, while in adults $\left(\mathrm{F}_{(3)}=5.37 ; P=0.011\right)$ and older adults $\left(\mathrm{F}_{(3)}\right.$ $=8.12 ; \mathrm{P}=0.002$ ) differences were observed in the forefoot. No differences were observed in foot regions not mentioned. When peak pressure variability was compared between the regions, regardless of the day of assessment, children showed higher variability in the midfoot, followed by the rearfoot and then forefoot $\left(\mathrm{F}_{(2)}=67.21 ; P<0.001\right)$. Among adults, higher variability also was observed in the midfoot, followed by the rearfoot and then forefoot $\left(\mathrm{F}_{(2)}=177.1\right.$; $\mathrm{P}<0.001$ ). Older adults showed higher peak pressure variability in the midfoot, while rearfoot and forefoot did not differ $\left(\mathrm{F}_{(2)}=177.1 ; \mathrm{P}<0.001\right)$.

We compared peak pressure variability between the groups and found that variability in the forefoot was higher in adults and older adults, which differed of children $\left(F_{(2)}=11.26 ; P=0.006\right)$. An age effect was also observed for rearfoot peak pressure variability $\left(F_{(2)}=6.21\right.$;
$P=0.010)$, which was higher in children compared to adults and older adults.

\section{Discussion}

In this study we set out to determine within and between-days repeatability of plantar pressure in participants from different age groups. Our main findings suggest that plantar pressure in the children and adults can be described by a single-day assessment, but elderly may require assessments in more than one day. Furthermore, foot region showing higher variability in peak pressure differs between age groups. It might be of special interest when analyzing peak pressure, which is frequently associated with sites of foot injuries. Additionally, our data show that measurement of plantar pressure variability is influenced by age and foot region.

The lack of difference between the steps for most of the variables obtained from a single-day assessment has two main implications. One concerns a methodological aspect, in which repeatability of the measurement increases as the number of records increases [18]. In the other hand, the lack of differences in the magnitude of pressure may reflect repeated loading over the foot regions. Is has been suggested that foot injuries depend on the magnitude of load, especially in the rearfoot [19] and the head of the metatarsals [20]. We observed that plantar pressure differed between some of the steps of 
children in the last day of assessment. However, differences were between a few particular steps and it is possible that after the repeated days of testing children were impatience and it might have affected their gait pattern. Despite of differences observed only in the last day, other possible explanation is the higher within-trials variability in spatial gait parameters, which is know to be higher among children [21].

Differences in mean plantar pressure between the foot regions were similar in children and adults (see Fig. 4). Children and adults showed smaller peak pressure in the midfoot and similar peak pressure in the rearfoot and forefoot. In the older adults higher peak pressure occurred in the forefoot, followed by rearfoot and midfoot. Higher peak of pressure in the forefoot in older adults may rely on altered foot sensitivity in the midfoot and rearfoot. According to a previous research [22], the forward shift in plantar pressure (away from the insensitive heel) constitutes a strategy of older adults to maintain balance. This hypothesis is reinforced by the results of variability in the peak pressure, which was higher in the forefoot of older adults and may be a strategy of older adults to promote propulsion during weight bearing [22].

Assuming that pressure did not differ between steps within each day, we compared the mean values between the fours days of measurement. Children and adults presented similar peak pressure in different days, but in older adults peak values differed between all the days. Children gait suffer continuous adaptations until the adulthood, and therefore some patterns of gait change very fast [23]. However, after reaching the adult age, patterns can be much more stable [14]. We observed that peak pressure varied between the days in older adults. One could argue that variability in the gait speed could determine the variability in peak pressure in older adults. However, gait speed variability in the older adults was $11.23 \%$, which is similar to the $12.80 \%$ observed in adults whom showed no differences in the peak pressure between the days. It is possible that variability in the peak pressure rely on tissue characteristics for impact absorption in the elderly, especially stiffness observed in the rearfoot and midfoot $[24,25]$. This hypothesis may find support on the higher variability in pressure observed among older adults in comparison to the other groups and the apparent higher dependence on forefoot sensitivity during weight bearing tasks [22].

The age group showed influence on pressure across the regions of the foot. Children and young adults showed similar patterns of plantar pressure distribution with pressure varying between the regions but higher in the rearfoot. In the older adult loading on midfoot was larger than in children and adults. The change in midfoot pressure may rely on increased stiffness in forefoot (hallux and metatarsal I, III and V) as result of aging
[25]. The higher variability in the peak pressure in forefoot among older adults can also be related to the change in foot landing pattern leading to longer contact time during support phase of gait [12].

Our study has inherent limitations. We opted for participants walking at preferred speed. Walking speed may affect plantar pressure and to minimize its effects we considered pressure data normalized to the foot total pressure. Participants were evaluated barefoot, which do not permit to infer on shod walking.

\section{Conclusion}

Plantar pressure in children and adults is consistent within and between-days. In other hand, plantar pressure in older adults requires measurements in different days to determine the plantar pressure, especially peak values.

\section{Acknowledgements}

PSF, RRA and FGC were supported by student fellowships from CAPES. FAPERGS granted this research to FPC (grant number 1013100).

\section{Funding}

FAPERGS granted this research to FPC (grant number 1013100). The agency had no role on the performance of the experiments or writing the paper, just provide financial resources to acquire instrumentation.

\section{Availability of data and materials}

Data can be made available upon request.

\section{Authors' contributions}

Experiment design: PSF and FPC

Data collection and analysis: PSF, CFM, MMF, RAR, FGC

Manuscript draft and critical review: PSF, CFM, MMF, RAR, FGC and FPC.

Approval of the final version: PSF, CFM, MMF, RAR, FGC and FPC.

\section{Ethics approval and consent to participate}

All participants signed a consent term agreeing to participate in this study. The committee of ethics in research approved this research with humans from the Federal University of Pampa (IRB 62011).

Consent for publication

Not applicable.

\section{Competing interests}

All authors declare that they had no financial or personal relationships with other people or organizations that could inappropriately influence their work.

\section{Publisher's Note}

Springer Nature remains neutral with regard to jurisdictional claims in published maps and institutional affiliations.

Received: 21 May 2018 Accepted: 15 June 2018

Published online: 11 July 2018

References

1. Gurney JK, Kersting UG, Rosenbaum D. Between-day reliability of repeated plantar pressure distribution measurements in a normal population. Gait \& posture. 2008;27:706-9.

2. Franco PS, Silva CB, Rocha ES, Carpes FP. Variability and repeatability analysis of plantar pressure during gait in older people. Rev Bras Reumatol. 2015;55: 427-33.

3. Deepashini H, Omar B, Paungmali A, Amaramalar N, Ohnmar H, Leonard J. An insight into the plantar pressure distribution of the foot in clinical practice: narrative review. Polish Annals of Medicine. 2014;21:51-6. 
4. Cousins SD, Morrison SC, Drechsler WI. The reliability of plantar pressure assessment during barefoot level walking in children aged 7-11 years. J Foot Ankle Res. 2012;5

5. Zammit GV, Menz HB, Munteanu SE. Reliability of the TekScan MatScan(R) system for the measurement of plantar forces and pressures during barefoot level walking in healthy adults. J Foot Ankle Res. 2010;3:11.

6. Bus SA, de Lange A. A comparison of the 1-step, 2-step, and 3-step protocols for obtaining barefoot plantar pressure data in the diabetic neuropathic foot. Clin Biomech (Bristol, Avon). 2005;20:892-9.

7. MCPoil TG, Cornwall MW, Dupuis L, Cornwell M. Variability of plantar pressure data. A comparison of the two-step and midgait methods. J Am Podiatr Med Assoc. 1999;89:495-501.

8. Hennig EM, Staats A, Rosenbaum D. Plantar pressure distribution patterns of young school children in comparison to adults. Foot \& ankle international. 1994;15:35-40.

9. Hennig EM, Rosenbaum D. Pressure distribution patterns under the feet of children in comparison with adults. Foot \& ankle. 1991;11:306-11.

10. Bosch K, Gerss J, Rosenbaum D. Preliminary normative values for foot loading parameters of the developing child. Gait \& posture. 2007;26:238-47.

11. Bosch K, Gerss J, Rosenbaum D. Development of healthy children's feetnine-year results of a longitudinal investigation of plantar loading patterns. Gait \& posture. 2010:32:564-71.

12. Scott G, Menz HB, Newcombe L. Age-related differences in foot structure and function. Gait \& posture. 2007;26:68-75.

13. Menz HB, Zammit GV, Munteanu SE, Scott G. Plantarflexion strength of the toes: age and gender differences and evaluation of a clinical screening test. Foot \& ankle international. 2006;27:1103-8.

14. Bosch K, Nagel A, Weigend L, Rosenbaum D. From "first" to "last" steps in life-pressure patterns of three generations. Clin Biomech (Bristol, Avon). 2009;24:676-81

15. Burns J, Crosbie J, Hunt A, Ouvrier R. The effect of pes cavus on foot pain and plantar pressure. Clin Biomech (Bristol, Avon). 2005;20:877-82.

16. Fernandez-Seguin LM, Diaz Mancha JA, Sanchez Rodriquez R, Escamilla Martinez E, Gomez Martin B, Ramos Ortega J. Comparison of plantar pressures and contact area between normal and cavus foot. Gait \& posture. 2014;39:789-92.

17. Shu L, Hua T, Wang YY, Li QA, Feng DD, Tao XM. In-shoe plantar pressure measurement and analysis system based on fabric pressure sensing Array. leee T Inf Technol B. 2010;14:767-75.

18. Hughes J, Pratt L, Linge K, Clark P, Klenerman L. Reliability of pressure measurements: the EM ED F system. Clin Biomech (Bristol, Avon). 1991;6:14-8.

19. Wong DW, Niu W, Wang Y, Zhang M. Finite element analysis of foot and ankle impact injury: risk evaluation of calcaneus and talus fracture. PLoS One. 2016:11:e0154435.

20. Zwitser EW, Breederveld RS. Fractures of the fifth metatarsal; diagnosis and treatment. Injury. 2010:41:555-62.

21. Stolze H, Kuhtz-Buschbeck JP, Mondwurf C, Johnk K, Friege L. Retest reliability of spatiotemporal gait parameters in children and adults. Gait \& posture. 1998;7:125-30.

22. Machado AS, Bombach GD, Duysens J, Carpes FP. Differences in foot sensitivity and plantar pressure between young adults and elderly. Arch Gerontol Geriatr. 2016;63:67-71.

23. Guffey K, Regier M, Mancinelli C, Pergami P. Gait parameters associated with balance in healthy 2- to 4-year-old children. Gait \& posture. 2016;43:165-9.

24. Hsu CC, Tsai WC, Chen CP, et al. Effects of aging on the plantar soft tissue properties under the metatarsal heads at different impact velocities. Ultrasound Med Biol. 2005;31:1423-9.

25. Kwan RL, Zheng YP, Cheing GL. The effect of aging on the biomechanical properties of plantar soft tissues. Clin Biomech. 2010;25:601-5.

\section{Ready to submit your research? Choose BMC and benefit from:}

- fast, convenient online submission

- thorough peer review by experienced researchers in your field

- rapid publication on acceptance

- support for research data, including large and complex data types

- gold Open Access which fosters wider collaboration and increased citations

- maximum visibility for your research: over $100 \mathrm{M}$ website views per year

At BMC, research is always in progress.

Learn more biomedcentral.com/submissions 